\section{Childhood in-hospital mortality from acute gastro-enteritis in Cape Town}

To the Editor: Acute gastro-enteritis (AGE) is a leading cause of childhood death in South Africa, HIV infection and malnutrition being associated diseases that increase the chances of death. Cape Town has a summer peak in AGE cases that taxes the health services. ${ }^{1}$ Since 2004, there has been a progressively more active system-wide approach to tackling the AGE incidence, morbidity and mortality. This involves the media, community and hospital services and progressive provision of basic amenities to the city's over 200 informal settlements. Though covering the whole metropolitan area, this plan focuses on areas with the highest child mortality from AGE.

In 2009, a data collection system was set up to monitor the scale and impact of the annual AGE peak from February to April that involved all 11 public hospitals (5 district, 3 regional and 3 central) in the city. All incident cases were counted on admission to a ward; inter-hospital transfers were not counted to avoid double counting. Deaths were counted, and information on co-morbid diseases such as HIV and malnutrition was collected on each death using the Child Healthcare Problem Identification Programme. ${ }^{2}$

In all, 3568 children were admitted during the 3-month period, approximately $1 \%$ of the city's estimated 333700 children under 5 years of age (Department of Health, unpublished data). The largest concentration of patients (1 476 patients, $41.4 \%$ of the total) was admitted to the Red Cross War Memorial Children's Hospital, which drains three sub-districts (under-5 population 137000 ) that contain areas with high social deprivation indices.

There were 37 deaths in hospitals; 9 occurred in emergency rooms (Table I). Notably, dehydration was the direct cause of death in a minority; associated disease led to death in most cases. Overall inpatient mortality in hospitals was $0.78 \%$, a low figure given the very demanding circumstances in many of the hospitals. The rate peaked at $1.2 \%$ in the busiest part of the season in March. The case fatality rate from the direct consequences of dehydration was $0.4 \%$, i.e. 1 in every 250 admissions.

These data have provided a first view of hospitalisation and in-hospital mortality due to AGE in a city in South Africa. Calculations based on figures from a worldwide review of the impact of diarrhoeal diseases suggest a lower population-based rate of hospitalisation for under- 5 year-olds of $0.6 \%$ in non-industrialised countries. ${ }^{3}$ That dehydration itself caused a minority of hospital deaths is encouraging, suggesting that programmatic attempts to prevent it at community and primary health care level are bearing fruit. The data also provide a baseline from which to measure the impact of attempts to mitigate the effects of AGE in Cape Town, including the recent roll-out of rotavirus vaccine in November 2009. We plan to analyse all AGE deaths in the city in future years, using a real-time notification system and death notification forms.

We thank all the people who kept and submitted the data on which this report is based. Permission to publish has been given by the Western Cape Department of Health.

\section{A Westwood \\ Co-ordinating Clinician, Paediatrics and Child Health \\ Western Cape Department of Health \\ anthony.westwood@uct.ac.za}

\section{J Claassen}

Director, Metropolitan District Health Services Western Cape Department of Health

On behalf of the Task Team on Childhood Diarrhoea in Cape Town

1. Bowie M, Westwood T, Ireland J. The Red Cross Children's Hospital Rehydration Unit: A 50-year review. South African Journal of Child Health 2007; 1: 26-32.

2. Patrick M, Stephen C. Child PIP: Making mortality meaningful by using a structured mortality review process to improve the quality of care that children receive in the South Africa health system. South African Journal of Child Health 2008; 2: 38-42.

3. Parashar UD, Hummelman EG, Bresee JS, Miller MA, Glass RI. Global illness and deaths caused by rotavirus disease in children. Emerg Infect Dis 2003; 9: 565-572.

Table I. Mortality from acute gastro-enteritis in Cape Town, February - April 2009

\begin{tabular}{|c|c|c|c|c|c|c|c|c|c|c|c|}
\hline \multirow{2}{*}{ Month } & \multirow{2}{*}{$\begin{array}{l}\text { Admissions } \\
\text { (total) }\end{array}$} & \multicolumn{2}{|c|}{ Deaths } & \multirow{2}{*}{$\begin{array}{c}\text { Due to } \\
\text { dehydration }\end{array}$} & \multicolumn{3}{|c|}{ Associated causes } & \multirow{2}{*}{$\begin{array}{l}\text { Total co- } \\
\text { morbidity }\end{array}$} & \multirow{2}{*}{$\begin{array}{l}\text { Total } \\
\text { deaths }\end{array}$} & \multirow{2}{*}{$\begin{array}{l}\% \text { due to } \\
\text { dehydration }\end{array}$} & \multirow{2}{*}{$\begin{array}{l}\text { Inpatient } \\
\quad \text { rate }(\%)\end{array}$} \\
\hline & & Casualty & Wards & & AIDS & Nutrition & Other & & & & \\
\hline February & 1106 & 2 & 3 & 4 & 0 & 1 & 0 & 1 & 5 & 80 & 0.28 \\
\hline March & 1369 & 4 & 17 & 7 & 8 & 3 & 3 & 14 & 21 & 33.3 & 1.24 \\
\hline April & 1093 & 3 & 8 & 3 & 6 & 0 & 2 & 8 & 11 & 27.3 & 0.73 \\
\hline Total & 3568 & 9 & 28 & 14 & 14 & 4 & 5 & 23 & 37 & 37.8 & 0.78 \\
\hline
\end{tabular}

